\title{
Experimental Investigation of Avocado Seed Oil Utilization in Diesel Engine Performance
}

\author{
Sutrisno ${ }^{1,2, *}$, Willyanto Anggono ${ }^{1,2}$, Fandi Dwiputra Suprianto ${ }^{1,2}$, Cokro Daniel Santosa ${ }^{1,2}$, \\ Michael Suryajaya ${ }^{3}$, and Gabriel Jeremy Gotama ${ }^{1,2}$ \\ ${ }^{1}$ Department of Mechanical Engineering, Petra Christian University, Jl Siwalankerto 121-131, \\ Surabaya, 60236, Indonesia \\ ${ }^{2}$ Centre for Sustainable Energy Studies, Petra Christian University, Surabaya, 60236, Indonesia \\ ${ }^{3}$ Department of Mechanical, Aerospace, and Automotive Engineering, Coventry University, Priory St, \\ Coventry, CV1 5FB, United Kingdom
}

\begin{abstract}
Avocado (Persea americana Mill) is a popular fruit in Indonesia. Its popularity leads to high consumption of this fruit and wastes from its seed. In order to develop renewable energy and reducing wastes in the environment, $P$. americana seed may be extracted for its oil to create biodiesel fuel. In this study, $P$. americana seed is obtained through the soxhlet apparatus and transesterification process. After obtaining $P$. americana seed oil, the oil was mixed with pure petro-diesel with a ratio of 10:90 (B10 fuel) and 20:80 (B20 fuel), respectively. These fuels were tested for their fuel characteristics and engine performances, together with pure petro-diesel and palm oil biodiesel. The fuel characteristics results suggest positive characteristics of $\mathrm{B} 10$ and $\mathrm{B} 20$ compared to other fuels. For engine performance tests, B10 and B20 fuels have less engine performance than other fuels. However, the differences between these fuels results are small. Overall, the positive aspect of B10 and B20 fuels supersede small disadvantages they have and thus suitable to substitute pure petro-diesel and palm oil biodiesel.
\end{abstract}

Keywords: Avocado fruit, biodiesel, fruit seed, Persea americana, renewable energy, waste oil

\section{Introduction}

As the population of human grows, the availability of energy source is depleted to help maintain a functioning society. Since people mainly rely on fossil fuel as their source of energy, its non-renewable attribute pushes its availability to the point of scarcity [1]. Furthermore, fossil fuels are also known to have a negative impact on the environment by producing GHG (greenhouse gases) as a result of its utilization [2]. In order to tackle this problem, studies have been conducted to provide alternative renewable energy sources that have small to no negative impact on the environment. The studies rely on an energy source that reduces human dependency on fossil fuel while also sustainable for a long period of

\footnotetext{
${ }^{*}$ Corresponding author: tengsutrisno@petra.ac.id
} 
time. Research on renewable energy has been done by using many available sources of energy around the human, such as wastes [3].

Studies on utilizing wastes as renewable energy gain momentum as they solve problems faced by many parts of our society. These studies help to encourage the use of waste and lead to a reduction of litters and a cleaner environment for people. Moreover, since wastes are also considered as litter, they are easily obtained without requiring an exorbitant cost. Many examples of renewable energy come from algae, industrial excess, agriculture crops and wastes, animal wastes, urban waste in solid form, wood wastes, and marine plants [4, 5]. In the form of biomass, renewable energy may be formed into briquette to maximize its potential as fuel $[3,6,7]$ or extracted for their oil to create biodiesel [8].

Among many potential wastes, Persea americana Mill fruit's seeds stand out as a prospective waste to be utilized as biodiesel in Indonesia. P. americana originates from Mexico, a tropical country with a similar environment as Indonesia. Because of the similar climate as Mexico, Indonesia is able to cultivate $P$. americana trees. Since $P$. americana is widely known in Indonesia for its health benefit $[8,10]$, the demand for P. americana fruits is high, and so is its production. After consuming $P$. americana fruits, their seeds, which are half of $P$. americana total mass, are usually thrown away and add more organic wastes. With such high availability of $P$. americana fruits in Indonesia, their wastes are easily obtained. Furthermore, by using $P$. americana fruit seeds as raw material for biodiesel, the number of organic wastes can be reduced to help in cleaning the environment of Indonesia.

Another advantage of using biodiesel fuel from $P$. americana seeds in Indonesia is its toxic attribute toward Aedes aegypti mosquitos' larvae, which when grow, may cause dengue fever to human. According to a study conducted by Torres et al. [9], the extracted $P$. americana ethanol and hexane have great larvicidal toxicity to Aedes aegypti mosquitoes. By utilizing $P$. americana seed oil as biodiesel, the exhaust of the engine may possibly help in controlling the population of Aedes aegypti. For a tropical country like Indonesia, which dengue fever is rampant, this advantage is a welcome addition to help Indonesia reduce the number of dengue fever patients.

Despite the advantages and studies that have been conducted to support the utilization of $P$. americana seed oil for biodiesel, only a few studies have investigated its performances in a diesel engine. Most studies support the usage of $P$. americana seed oil from its chemical composition studies and ease of extraction [11, 12]. For that reason, this study was conducted to understand the potential of biodiesel derived from P. americana seed oil as a substitute for conventional diesel fuel.

\section{Experimental methods}

This research is conducted by initially collecting wastes of $P$. americana seeds. The picture of collected $P$. americana seeds is displayed in Figure 1(a). The collected $P$. americana seeds were then dried using sunlight to decrease their water content as much as $40 \%$ of their total weight. The process of sun drying the $P$. americana seeds can be seen in Figure 1(b). After sun-dried, the skins of the P. americana seeds were peeled. The peeled $P$. americana seeds were then pounded into powder. The result of pulverizing the $P$. americana seeds is presented in Figure 1(c). After turned into powder, the $P$. americana seeds were extracted for their oil using Soxhlet extractor and n-hexane solvent. The design of the Soxhlet apparatus is shown in Figure 2(a) while the picture of the Soxhlet apparatus used in this study is shown in Figure 2(b).

The process of oil extraction using soxhlet was initialized by placing the $n$-hexane in the lower reservoir. The n-hexane was then heated to the boiling temperature of $60{ }^{\circ} \mathrm{C}$ to $65{ }^{\circ} \mathrm{C}$. The vapor from boiling n-hexane moved upward through the tube, reaching the grounded seed and then condensed into a liquid. During the encounter of n-hexane 
evaporation and $P$. americana seeds, the n-hexane bound the oil inside the $P$. americana seeds. The condensed liquid contained both n-hexane and extracted P. americana seed oil. Afterward, both the n-hexane and $P$. americana seed oil extract returned to the lower reservoir. As the process continued, the concentration of $P$. americana seed oil in the lower reservoir increased until the $P$. americana seed oil was completely extracted.

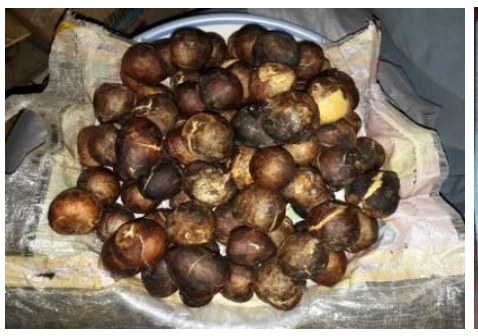

(a)

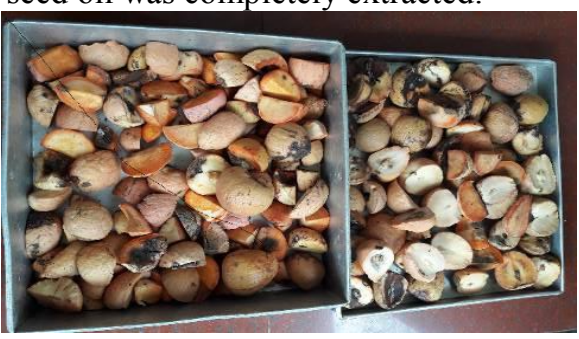

(b)

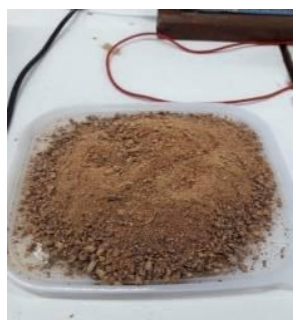

(c)

Fig. 1. Persea americana seed in (a) after collected in its raw state, (b) sun-dried to reduce its moisture content, (c) pulverized into powder for Soxhlet extraction.

After obtaining both n-hexane and $P$. americana seed oil extraction mixture displayed Figure 3(a), the n-hexane used in Soxhlet extraction needs to be separated. The mixture was separated using a rotary evaporator and vacuum controller. The rotary evaporator was operating under a temperature of $60{ }^{\circ} \mathrm{C}$. The pressure of vacuum condition was set for 360 mBar using the vacuum controller. Figure 3(b). shows the extracted $P$. americana seed oil after purification process using rotary evaporator. After purifying the mixture, the final volume of $P$. americana seed oil extraction was $40 \%$ of the original mixture volume obtained during soxhlet extraction.

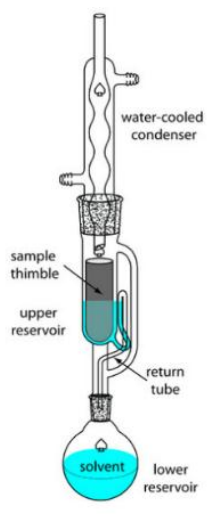

(a)

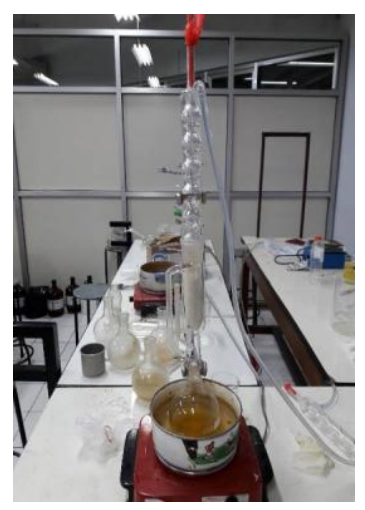

(b)

Fig. 2. Soxhlet apparatus (a) design and (b) assembled to be used in this study for extracting $P$. americana seeds oil. 


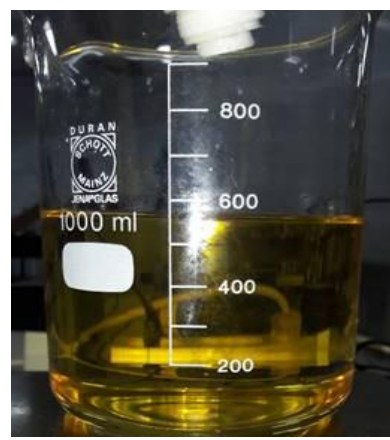

(a)

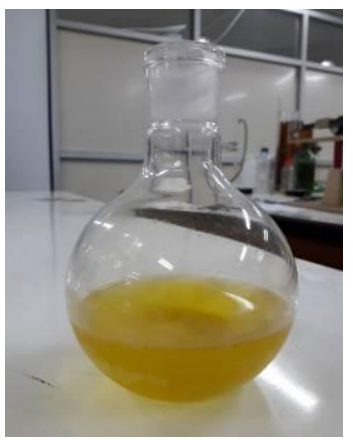

(b)

Fig. 3. Extracted $P$. americana seed oil (a) after Soxhlet extraction with both $n$-hexane and $P$. americana seed oil mixture and (b) after purification process using rotary evaporator.

After acquiring purified $P$. americana seed oil, the acquired seed oil went through the trans-esterification process. Transesterification process is the process of changing vegetable oil, including $P$. americana seed oil, to biodiesel. Transesterification works by removing the complex fatty acid (triglyceride molecule), counteracting the free fatty acids, removing the glycerine and produce ester alcohol. This process required $20 \%$ methanol and $1 \% \mathrm{Na}-$ $\mathrm{OH}$ of the total weight of the oil, which took approximately two days for the separation of methyl esters and the glycerine content in P. americana seed oil. The separation is apparent with the naked eye due to the density difference between methyl esters and glycerine. Fig. 4(a) shows the condition of the transesterification process an hour after methanol and Na$\mathrm{OH}$ addition. Figure 4(b) shows the condition of transesterification process $2 \mathrm{~d}$ after methanol and $\mathrm{Na}-\mathrm{OH}$ addition.

The result of the methyl esters acquired from transesterification is referred to as $P$. americana seed bio-oil. This bio-oil was then examined for its feasibility to be used as a substitute for diesel fuel. The examinations were conducted by studying both the bio oil's fuel characteristics and its performances in the diesel engine. The bio-oil was mixed with pure petrodiesel fuel with $10 \%$ and $20 \%$ of the pure petrodiesel fuel total weight. The tests to determine the fuel characteristics were conducted under ASTM standard. The detail of which standard was used to perform the test is given in Table 1. The results of the fuel characteristics tests were compared with pure petro-diesel and commercial biodiesel fuel made from palm oil in Indonesia (palm oil biodiesel). As for the engine performance tests, the tests were conducted using dynamometer and the results were also compared with pure petro-diesel and palm oil biodiesel.

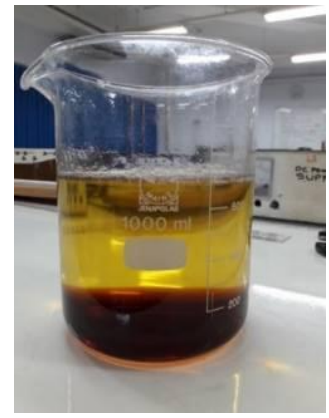

(a)

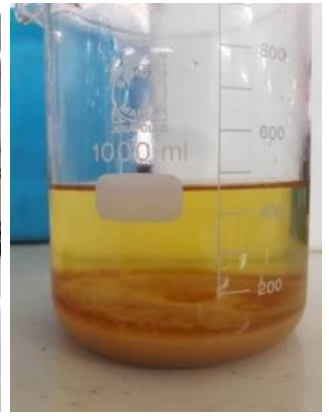

(b)

Fig. 4. Transesterification process during (a) $1 \mathrm{~h}$ after addition of methane and $\mathrm{Na}-\mathrm{OH}$ and (b) $2 \mathrm{~d}$ after addition of methane and $\mathrm{Na}-\mathrm{OH}$ 
Table 1. Test method standard for fuel characteristics investigation

\begin{tabular}{lcl}
\hline \multicolumn{1}{c}{ Properties } & Unit & Test method \\
\hline Density at $15{ }^{\circ} \mathrm{C}$ & $\mathrm{Kg} \mathrm{L}^{-1}$ & ASTM D-1298 \\
Viscosity kinematic at $40{ }^{\circ} \mathrm{C}$ & $\mathrm{cSt}$ & ASTM D-445 \\
Flash point & ${ }^{\circ} \mathrm{C}$ & ASTM D-93 \\
Pour point & ${ }^{\circ} \mathrm{C}$ & ASTM D-97 \\
Sulphur content & $\% \mathrm{wt}$ & ASTM D-4294 \\
ASTM colour & - & ASTM D-1500 \\
Water content & $\mathrm{ppm}^{*}$ & ASTM D-6304 \\
Cetane index & - & ASTM D-4737 \\
Distillation at $90 \%$ recovery & ${ }^{\circ} \mathrm{C}$ & ASTM D-86 \\
\hline${ }^{*} \mathrm{mg} \mathrm{L}^{-1}$ is SI for ppm & &
\end{tabular}

\section{Results and discussion}

The results of this study consist of investigation of fuel characteristics and engine performances of $P$. americana seed Bio-diesel. Figure 5 and Figure 6 present the fuel characteristics tests result for pure petro-diesel (Diesel), palm oil biodiesel (Bio-Diesel), $10 \% P$. americana seed oil and $90 \%$ pure petro-diesel mixture (B10), and $20 \%$ $P$. americana seed oil and $80 \%$ pure petro-diesel mixture (B20).

Figure 5 shows the sulfur content, density, colour, and kinematic viscosity of pure petro-diesel, palm oil biodiesel, B10, and B20 fuel. The sulphur content investigation indicates biodiesel B10 and B20 from P. americana seed oil have lower sulphur content than pure petro-diesel and palm oil biodiesel. With lower sulphur content, corrosivity of the engine decreases, and their emission are more environmentally friendly. B20 fuel has lower sulphur content compared to B10 fuel. This indicates that the increase of $P$. americana seed oil content my further reduce the sulphur content in pure petro-diesel. For density investigation, the results show no significant density differences between fuels. The increase of $P$. americana seed oil content in the fuel mixture raises the density of the fuel. Colour investigation shows that pure petro-diesel, B10, and B20 have a similar colour point of 2.5 while palm oil biodiesel has a colour point of 3 . In kinematic viscosity investigation, it was discovered that the increase of $P$. americana seed oil in pure petro-diesel further raises the density of fuel mixture. Palm oil biodiesel has the highest kinematic viscosity compared to other fuels tested.

Figure 6 shows the pour point, high heating value (HHV), cetane index, flash point, water content, and distillation point of pure petro-diesel, palm oil biodiesel, B10, and B20 fuel. The pour point investigation shows that the higher percentage of $P$. americana seed oil in pure petro-diesel raises the pour point. Fuel with the highest pour point was found to be palm oil biodiesel. For high heating value investigation, the results show the addition of $10 \%$ P. americana seed oil decreases the HHV of the fuel mixture while the addition of $20 \%$ P. americana seed oil increases the HHV of the fuel mixture. Palm oil biodiesel has the highest HHV among all fuels tested. Investigation of cetane index characteristic results shows that the addition of $10 \% P$. americana seed oil reduces the cetane index while the addition of $20 \% P$. americana seed oil raises the cetane index. Palm oil biodiesel has the highest cetane index among all fuels tested. The flash point investigation indicates the increase of $P$. americana seed oil percentage in pure petro-diesel my further reduces the flash point. The water content of fuels tested shows the decrease of water content with $10 \%$ $P$. americana seed oil addition to pure petro-diesel while $20 \%$. americana seed oil addition raises the water content of the mixture. Lastly, the distillation point investigation shows the increase of distillation point with the addition of $P$. americana seed oil. An additional percentage of $P$. americana seed oil from $10 \%$ to $20 \%$ has miniscule effect in raising the distillation point. 


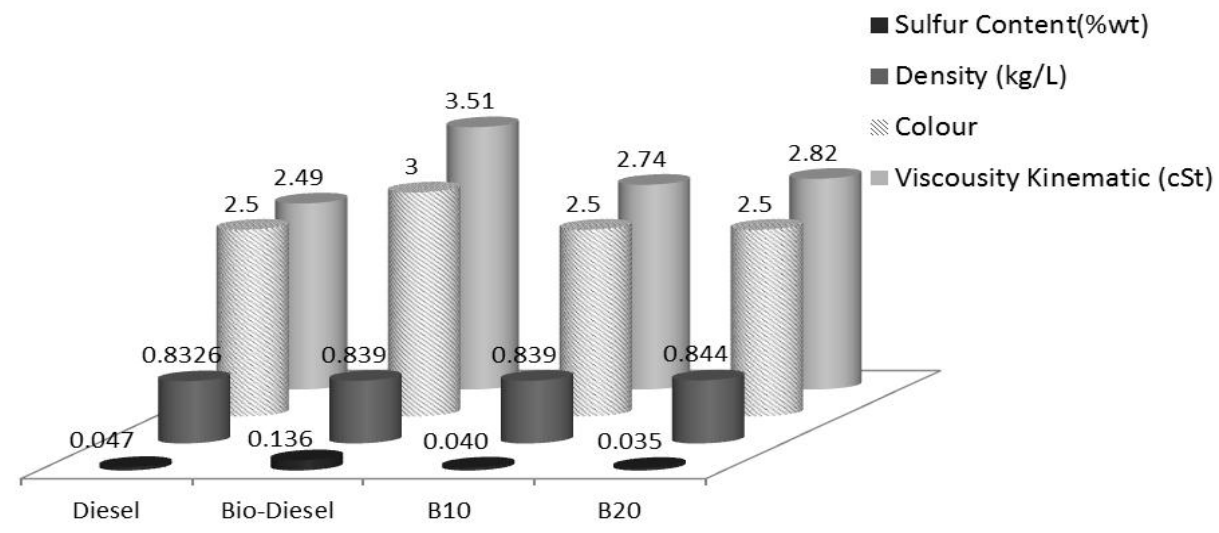

Fig. 5. Results of fuel characteristics test for sulphur content, density, colour, and viscosity kinematic.

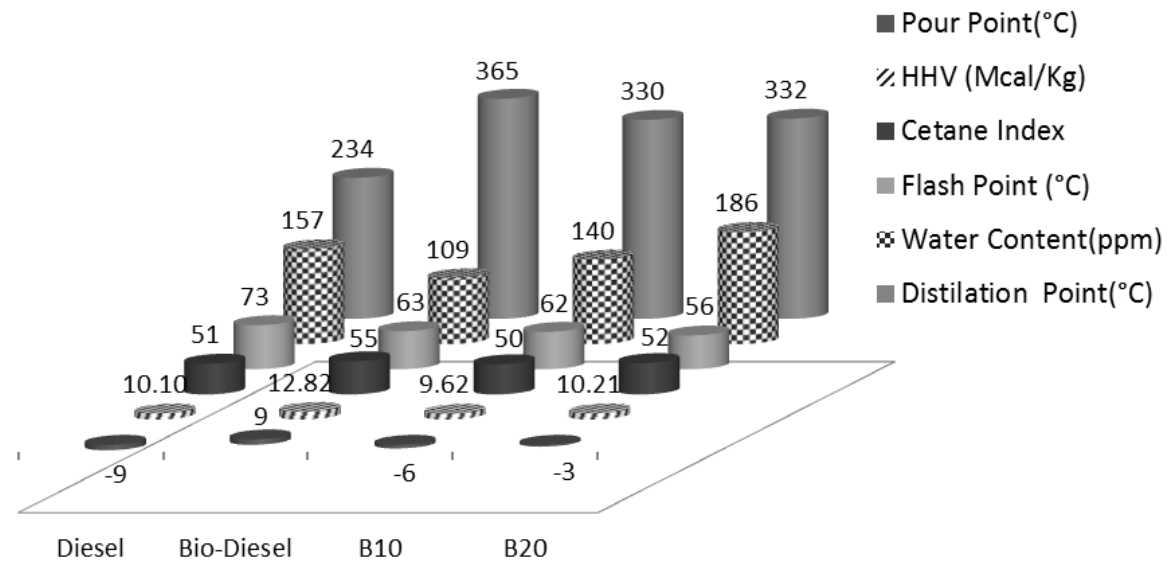

Fig. 6. Results of fuel characteristics test for pour point, high heating value (HHV), cetane index, flash point, water content, and distillation point.

Figure 7 shows the results of engine performance test in term of brake power and torque for pure petro-diesel (Diesel), palm oil biodiesel (Biosolar), $10 \%$. americana seed oil and pure petro-diesel mixture (B10), and $20 \% P$. americana seed oil and pure petro-diesel mixture (B20). Figure 7(a) shows the results of the engine Brake power performance test. The test results show lower brake power output in B10 and B20 fuel compared to pure petro-diesel and palm oil biodiesel. However, the decrease of the brake power output is small. The decrease only reaches as much as $3.82 \%$ for B10 and $2.39 \%$ for B20 from pure petro-diesel brake power output. The highest brake power output found in this investigation was from pure petro-diesel with $30.86 \mathrm{~kW}$ at $2200 \mathrm{rpm}(1 \mathrm{rpm}=1 / 60 \mathrm{~Hz})$. At this engine speed, the brake power output of B10 and B20 is $29.69 \mathrm{~kW}$ and $30.13 \mathrm{~kW}$, respectively. This investigation also discovers the possibility that the brake power output is positively proportional to the raise of $P$. americana oil concentration in the fuel mixture.

Figure 7(b) displays the investigation of torque in engine performance tests. The torque results show that $\mathrm{B} 10$ and $\mathrm{B} 20$ have lower torque compared to pure petro-diesel and palm oil biodiesel. The highest torque was performed by utilizing palm oil biodiesel fuel with 142.17 Nm during $2000 \mathrm{rpm}$ engine speed. Albeit B10 and B20 have lower torque compared to other fuels, the difference of torque value between these fuels is slim. 


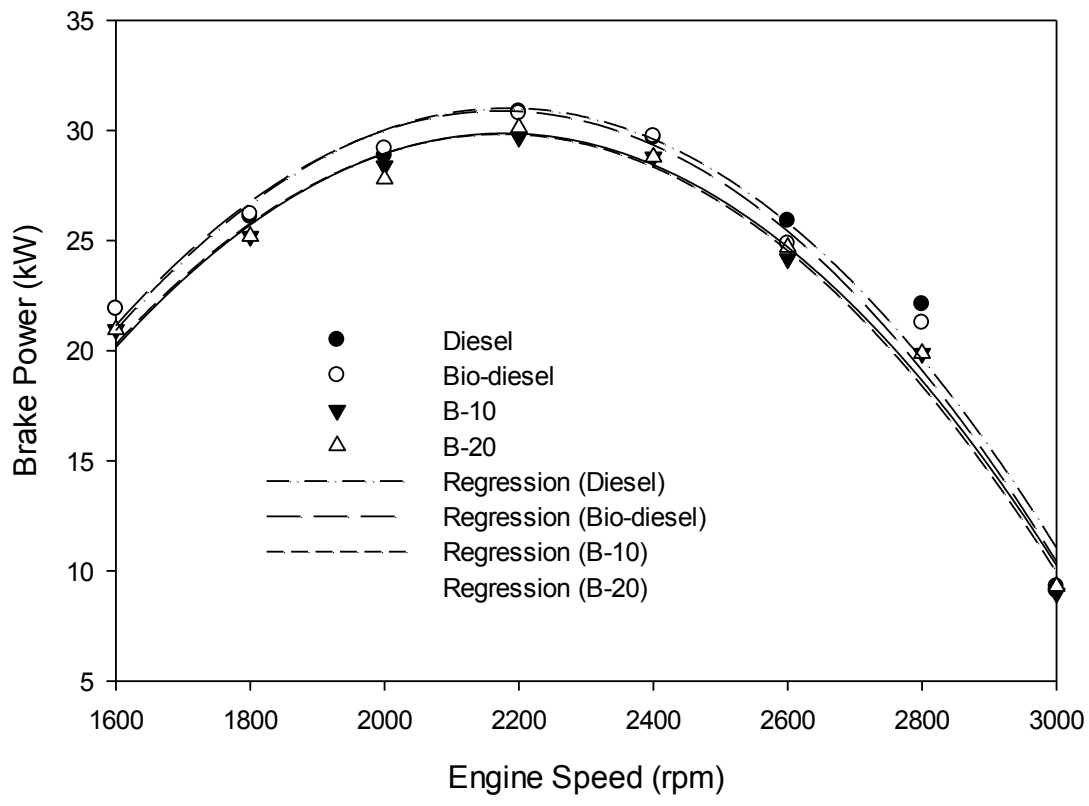

(a)

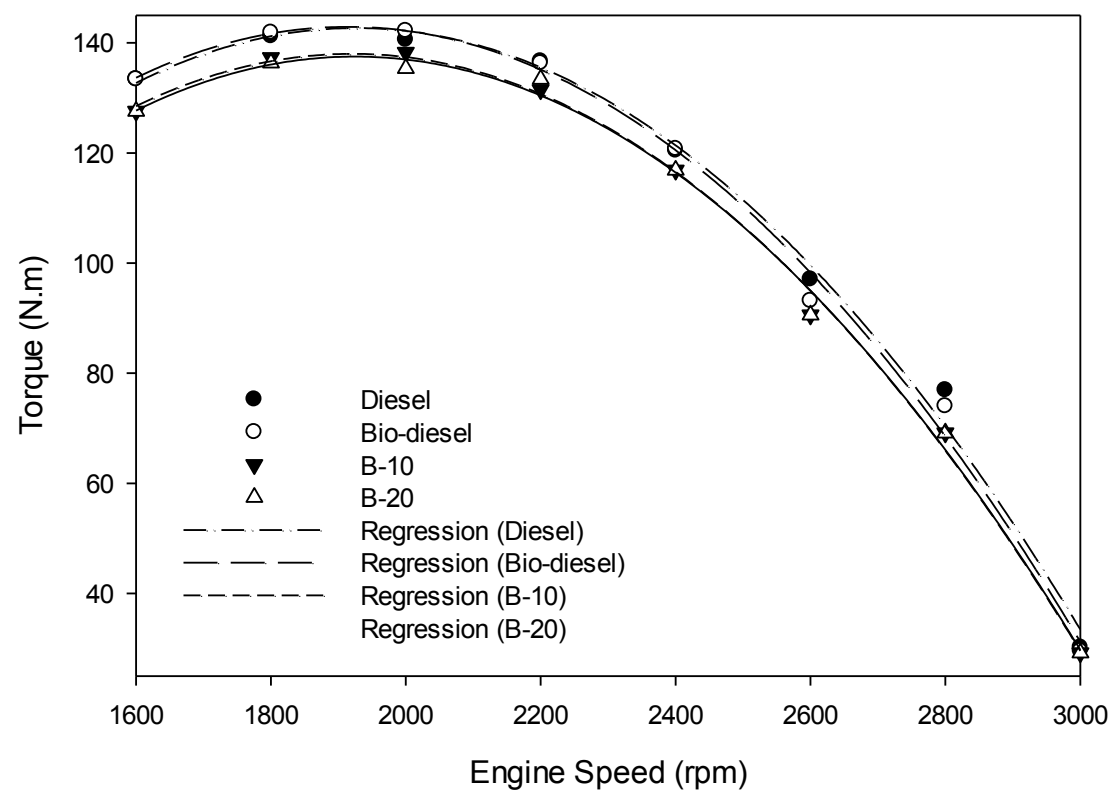

(b)

Fig. 7. Engine performance test results for various fuels in terms of (a) Brake power output of the engine and (b) Torque of the engine.

Figure 8 displays the brake thermal efficiency and brake specific fuel consumption (BSFC) for pure petro-diesel (Diesel), palm oil biodiesel (Bio-diesel), $10 \%$ P. americana 
seed oil and pure petro-diesel mixture (B10), and $20 \%$. americana seed oil and pure petro-diesel mixture (B20). Figure 8(a) shows the engine performance test for brake thermal efficiency. The thermal brake efficiency in low and middle engine speed show apparent differences between fuels except for pure petro-diesel with higher brake thermal efficiency than the rest of the fuels. In high engine speed, the differences in thermal brake efficiency between fuels become more apparent with B10 and B20 fuels having lower the brake thermal efficiency. The brake thermal efficiency differences between pure petrodiesel to B10 and B2 become higher as the engine speed are increases.

Figure 8(b) shows the Brake specific fuel consumption (BSFC) of various fuels acquired from engine performance test. From this figure, it can be seen that under low engine speed, the BSFC of B10 is lower than the rest of the fuels tested. In the middle level of engine speed, BSFC for B10 fuel starts to raise while BSFC for B20 raises in a much smaller magnitude within the same range as pure petro-diesel and palm oil biodiesel. In high engine speed, the BSFC for B10 value significantly raises compared to other tested fuels. B20 fuel in the high-speed engine has its BSFC raises. However, the BSFC raise for B20 fuel is within a considerable range of both pure petro-diesel and palm oil biodiesel.

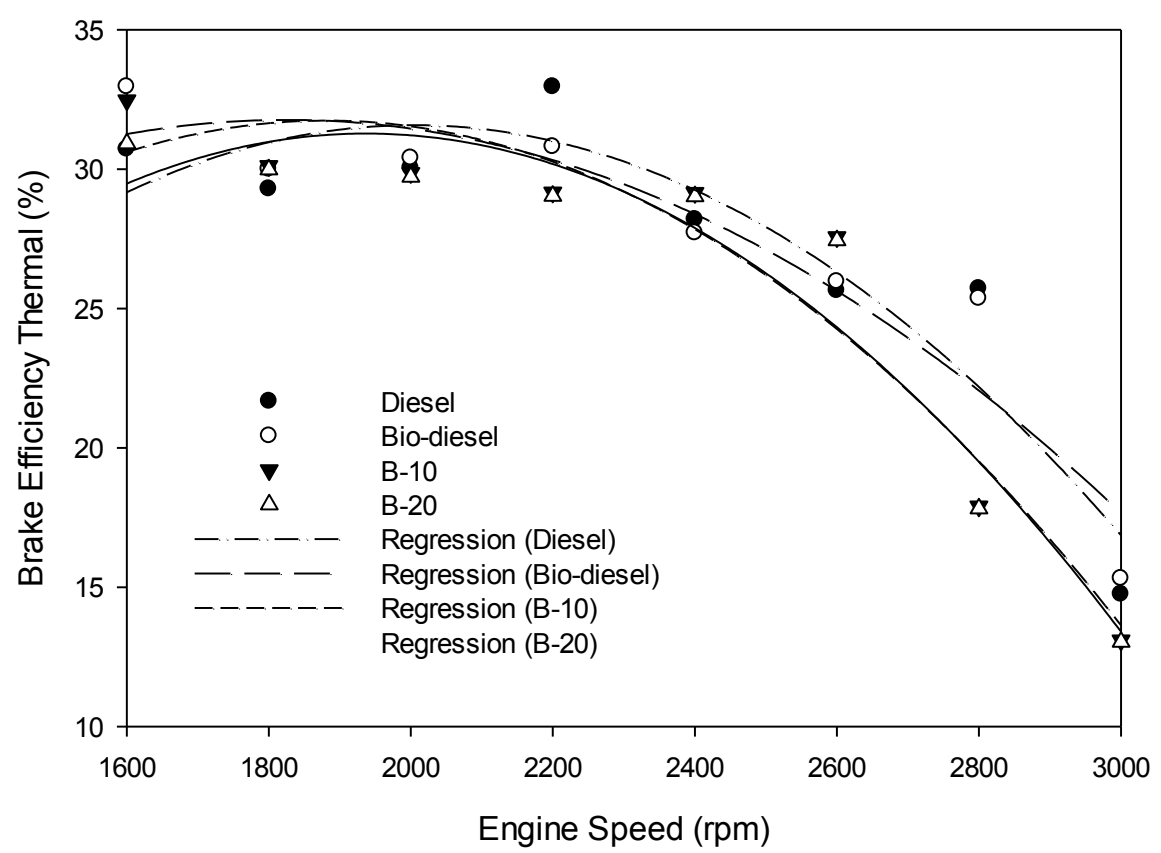

(a) 


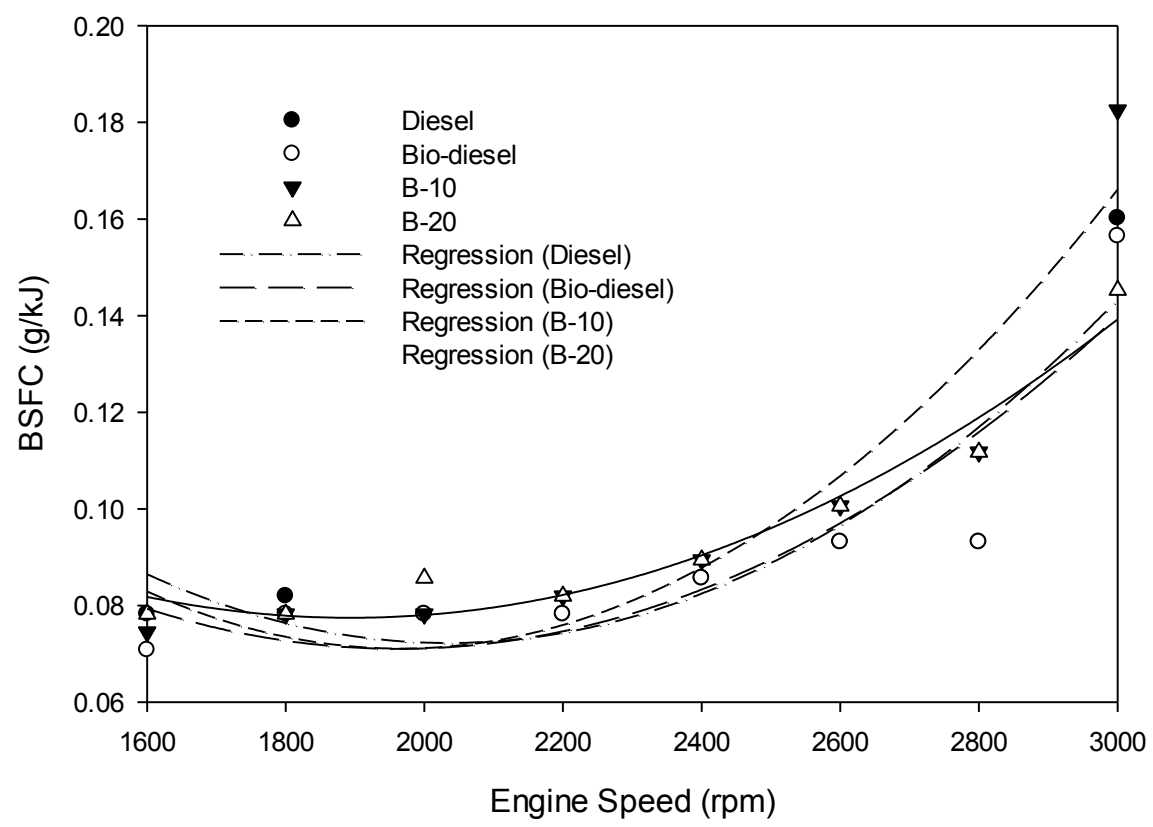

(b)

Fig. 8. Engine performance test results for various fuels in terms of (a) Brake thermal efficiency of the engine and (b) Brake specific fuel consumption of the engine.

\section{Conclusions}

From fuel characteristics tests, it can be concluded that pure petrodiesel mixed with $10 \%$ and $20 \% P$. americana seed oil has several advantages and are comparable to pure petrodiesel and palm oil biodiesel. Pure petrol-diesel mixed with $P$. americana seed oil has lower sulfur content compared to both pure petro-diesel and palm oil biodiesel. Fuel from pure petrodiesel mixed with $P$. americana seed oil also has higher HHV compared to pure petrodiesel.

The engine performance tests indicate the possibility of utilizing $P$. americana biodiesel fuel. The tests result for power and torque show comparable performance between $P$. americana biodiesel fuel and commercial fuels. For thermal efficiency and specific fuel consumption, the quality of $P$. americana biodiesel fuel is comparable to both pure petrodiesel and palm oil biodiesel under low and middle engine speed. In high engine speed, $P$. americana biodiesel has less performance than pure petro-diesel and palm oil biodiesel in term of thermal efficiency and specific fuel consumption.

Although $P$. americana biodiesel fuel has lower engine performance characteristics compared to pure petro-diesel and palm oil biodiesel, the low sulfur content attribute in $P$. americana biodiesel makes it a viable, environmentally friendly substitute. Today, as the awareness to sustain clean environment raises, the environmentally friendly fuel is an alternative for traditional fossil fuels. 


\section{References}

1. M. Höök, X. Tang, Ene. Policy, 52:797-809(2013).

https://ideas.repec.org/a/eee/enepol/v52y2013icp797-809.html

2. M. Meinshausen, N. Meinshausen, W. hare, S.C.B. Raper, K. Frieler, R. Knutti, D.J. Frame, and M.R. Allen, Nature, 458:1158-1163(2009).

https://www.ncbi.nlm.nih.gov/pubmed/19407799

3. W. Anggono, Sutrisno, F.D. Suprianto, J. Evander, IOP Conf. Ser.:Mater. Sci. Eng., 241:012043(2017). $\quad$ https://iopscience.iop.org/article/10.1088/1757$\underline{\text { 899X/241/1/012043 }}$

4. Shri AMM Murugappa Chettiar Research Center, Biomass Charcoal Briquetting: Technology for Alternative Energy Based Income Generation in Rural Areas [Online] from https://www.researchgate.net/publication/236846135 (2010). [Accessed on January $17^{\text {th }} 2018$ ]

5. Ministry of Energy and Mineral Resources Republic of Indonesia, 2017 Handbook of Energy \& Economic Statistics of Indonesia [Online] from https://www.esdm.go.id/assets/media/content/content-handbook-of-energyeconomic-statistics-of-indonesia-2017-.pdf (2017). [Accessed on January $17^{\text {th }}$ 2018]

6. Sutrisno, W. Anggono, F.D. Suprianto, A.W. Kasrun, I.H. Siahaan, ARPN J. of Eng. and App. Sci., 12,4:931-936(2017).

http://www.arpnjournals.com/jeas/volume_04_2017.htm

7. W. Anggono, F.D. Suprianto, Sutrisno, G.J. Gotama, J. Evander, A.W. Kasrun. ARPN J. of Eng. and App. Sci., 13,3:1080-1084(2018). http://www.arpnjournals.com/jeas/volume 03 2018.htm

8. E. Buyukkaya. Fuel, 89:3099-3105(2010). https://www.sciencedirect.com/science/article/pii/S0016236110002590

9. R.C. Torres, A.G. Garbo, R.Z.M.L. Walde. Asian Pacific J. of Tropical Med. 7,1:S167-S170(2014). https://www.sciencedirect.com/science/article/pii/S199576451460225X

10. U.E. Echenna, A.B. Shori, A.S. Baba. Revista Argentina de Endocrinología Y Metabolismo, 54,3:140-148(2017). https://www.sciencedirect.com/science/article/pii/S0326461017300384

11. T. Hiwot. Chem. Inter., 3,3:311-319(2017). http://bosaljournals.com/chemint/images/pdffiles/84.pdf

12. T. Aysu, H. Durak. Biofuels, Bioproducts and Biorefining, 9,3:1-27(2015). https://onlinelibrary.wiley.com/doi/10.1002/bbb.1535 